\title{
O Fórum Social Mundial e a agenda da educação popular
}

\author{
Danilo Romeu Streck
}

Universidade do Vale do Rio dos Sinos, Programa de Pós-Graduação em Educação

É o sonho que liberta. De tudo: do mundo, dos outros, de nós. É necessário crer no sonho. E salvá-lo sempre. Para nos salvarmos. Para deixarmos a face radiosa de nossa alegria no último ermo, e na última sombra, onde outras vidas, depois, vierem um dia perguntar as coisas que hoje andamos nos perguntando.

Cecília Meireles

[...] talvez a ideia correcta seja a de que o futuro é somente um imenso vazio, a de que o futuro não é mais que o tempo de que o eterno presente se alimente. Se o futuro está vazio, pensou Tertuliano Máximo Afonso, então não existe nada a que possa chamar domingo, a sua eventual existência depende da minha existência, se eu nesse momento morresse, uma parte do futuro ou dos futuros possíveis ficaria para sempre cancelada.

José Saramago

\section{Um catalisador de sonhos}

O Fórum Social Mundial, realizado em sua terceira edição na cidade de Porto Alegre (Brasil) entre os dias 23 e 28 de janeiro de 2003, impressionou pelos números e pela diversidade de atividades das quais mais de 100 mil pessoas oriundas de 156 países puderam participar. Conferências, seminários, oficinas, reuniões, fóruns por áreas (publicitários, juízes, prefeitos, entre muitos outros), passeatas e shows artísticos compuseram um cenário de beleza e de vibração inigualável. O clima celebrativo que perpassou todas as atividades, mesmo as reflexões mais sérias, contrastava com as notícias sobre o clima depressivo que reinava na reunião dos poderosos no Fórum Econômico Mundial em Davos (Suíça).

A abrangência do evento também torna impossível uma apropriação de todas as discussões que ocorreram, numa espécie de grande síntese. O que se vê e lê em jornais e revistas são retratos baseados em determinados pontos de vista. Alguns falam em nome da coordenação do Fórum, outros centram seu olhar numa especialidade acadêmica ou enfocam algum tema relevante para o seu contexto político e social. Mesmo assim, há uma identificação de fundo entre as pessoas e os grupos que se encontram no Fórum desde 2001, sob o lema "Um outro mundo é possível". 
Esta identificação está muito mais no partilhamento das mesmas esperanças e na busca de alternativas que se deseja realizar junto com outros do que na luta por projetos específicos, embora estes comecem a aparecer com mais freqüência na medida em que o Fórum assume explicitamente uma postura mais propositiva. Acima de tudo, o Fórum permite promover a sintonia entre linguagens diferentes, numa espécie de Pentecostes $^{1}$ político em que cada um se expressa em sua língua e todos acabam se entendendo.

Não seria exagerado referir-se a ele como um imenso catalisador de sonhos, ${ }^{2}$ um lugar onde se procura inspiração e propostas para refazer o presente a partir de "empréstimos" que se faz do futuro. As frases em epígrafe, respectivamente de Cecília Meireles e de José Saramago, têm a intenção de apontar para a importância de não ceder ao realismo dos projetos imediatos. Meireles nos fala que salvando o sonho damos uma chance a nós mesmos. A dúvida do personagem de Saramago coloca o futuro como um imenso vazio, melhor, uma enorme câmara onde se situam também os nossos "domingos".

Essa catalisação de sonhos concretiza-se sobretudo na elaboração de uma agenda geral comum, ou de agendas menores que vão se compondo como num imenso mosaico. ${ }^{3}$ Um dos méritos do Fórum está nesta conquista da possibilidade de gerar agendas originadas na vida da sociedade, e não simplesmente assu-

${ }^{1}$ Assumo a imagem de Pentecostes porque vejo nela a diversidade em busca de unidade e entendimento (os seguidores de Jesus falavam outras línguas e cada um entendia o que o outro dizia na sua própria língua), enquanto Babel é, primeiro, signo da presunção humana e, depois, da fragmentação dispersiva como castigo.

${ }^{2} \mathrm{O}$ filósofo húngaro István Mészáros referiu-se ao Fórum Social Mundial como "catalisador revolucionário". Ao privilegiar a metáfora dos sonhos, tenho a intenção de destacar a criação de um imaginário comum, capaz de abrigar uma grande diversidade de projetos.

${ }^{3}$ No I Fórum foi formado um enorme mosaico com pedras trazidas pelos participantes de todos os cantos do mundo. mir os problemas definidos a partir da conjuntura econômica e dos humores do mercado. "Nosso propósito", dizia Bernard Cassen (2001) ao refletir sobre os objetivos da criação do Fórum Social Mundial, "era mostrar que o encontro de Porto Alegre colocaria os interesses das sociedades, e não os da economia e das finanças, no posto de comando" (p. 16). O Fórum de Davos apareceria daí para diante pelo que sempre foi: uma reunião de interesses corporativos.

Embora tenha havido, dias antes do Fórum Social Mundial, um encontro específico de educadores, o II Fórum Mundial de Educação, com aproximadamente 15 mil participantes, acredito que seja nos embates multidisciplinares do primeiro que devemos procurar os desafios para a educação. É ali, onde a educação se encontra misturada com inúmeras expressões da vida, que se pode reinventar a pedagogia como um dos meios para sonhar e criar esse outro mundo.

No caso deste artigo, tenho como perspectiva a educação popular, entendida a partir de seu compromisso explícito com a criação de um outro mundo, pelo seu jeito sempre esquivo a esquemas, porque se reinventa com e através do povo em movimento. Foi com essa intenção que a expressão se firmou na América Latina enquanto ação pedagógica, política e cultural integrante do grande movimento de libertação que foi se configurando como pedagogia do oprimido, teologia da libertação, teatro do oprimido e cultura popular. Mais relevante que partir de alguma conceituação de educação popular como uma teoria, proposta pedagógica ou conjunto de metodologias, é concebê-la como o trabalho com o saber inserido na busca de um outro viver-junto que homens e mulheres - por opção, vocação, ou simplesmente por necessidade - realizam ao se compreenderem como seres de cultura, produtores de suas vidas. É melhor compreendê-la, segundo Brandão (2002), como "o imaginário e a vocação múltipla" ancorados em escolhas. "Escolhas de sujeitos, de modos de interação, de sentidos e de significados dados a destinos humanos através do saber. Escolhas que, uma vez estabelecidas, podem ser pensadas dentro de mais de uma teo- 
ria e podem ser realizadas por meio de mais do que um método" (p. 41).

Brandão também nos desafia a ver o povo não pelas lentes de algumas "abstrações" como classes ou movimentos sociais, mas a partir do rosto concreto que nos interpela na forma dos meninos de rua que encaramos entre medo e pena, dos negros ou índios que insistimos em deixar no "seu" devido lugar, dos alunos e das alunas que são "clientes" ou "matéria" para projetos de futuro... Enfim, são rostos e corpos antes de serem frações de classes e grupos. Isso evidentemente não nos exime do esforço de definições e abstrações, necessárias para situar-nos na multifacetada dinâmica da vida, mas coloca um outro ponto de partida.

Antes de identificar pautas de uma agenda para a educação popular originadas do Fórum Social Mundial, detenho-me brevemente no próprio Fórum. Trata-se de uma tentativa de fazer sentido deste imenso ponto de encontro ${ }^{4}$ que se tornou uma das mais importantes expressões da sociedade civil contemporânea.

\section{A sociedade em movimento}

O Fórum não é apenas um evento anual, mas passou a ser um movimento que se realiza em muitos tempos e lugares. Existe um encontro anual (os três primeiros foram em Porto Alegre e o próximo será na Índia), mas seria uma compreensão demasiado limitadora restringir o Fórum a este encontro. O Fórum Social Mundial é, antes de tudo, a manifestação do povo em movimento. Numa de suas últimas entrevistas, referindo-se à marcha dos sem-terra a Brasília, Paulo Freire comentava seu sonho de ver uma infini-

${ }^{4}$ Francisco Witaker Ferreira compara o Fórum Social Mundial a uma grande praça que, embora tenha os seus contornos definidos, não propõe uma agenda fechada e também não conclui com um documento ou uma carta representativa ou consensual do evento. Ele vê nessa abertura um dos motivos para o seu sucesso (Aula inaugural do Centro de Ciências Humanas, UNISINOS, em 6 de março de 2003). dade de marchas: dos sem-teto, dos reprovados na escola, dos sem-amor... O Fórum Social Mundial representa um pouco essa confluência de marchas de pessoas que acreditam que há outros mundos possíveis e viáveis.

De onde vem esse movimento e o que ele tem a ver com a América Latina? Esta pergunta é, a meu ver, a chave para reposicionar a própria educação popular. Poderíamos trabalhar com a hipótese de que se trata simplesmente de mais uma moda importada e que se acabou concretizando casualmente numa cidade de pouca expressão internacional. O Fórum Social Mundial representaria, inclusive, uma espécie de invasão e deturpação de um processo lento e penosamente construído ao longo das quatro últimas décadas. A hipótese com que trabalho é outra, ou seja, de que o Fórum Social Mundial é a expressão global de inúmeras frentes de luta por libertação, em todos os continentes, que buscam pontos de confluência. A localização do Fórum numa cidade da América Latina também não é casual, mas deve-se à experiência de mobilização e organização dos movimentos populares nessa parte do mundo. A constituição do Partido dos Trabalhadores (PT), tendo como um dos princípios a participação popular, é parte desse processo de organização popular e constituiu um fator importante para a vinda do Fórum ao Brasil. Ao mesmo tempo, no entanto, o Fórum desafia esses movimentos a reverem suas agendas, buscando sintonia com linguagens e realidades às vezes pouco conhecidas.

Em geral, considera-se que os antecedentes mais imediatos do Fórum Social Mundial são as manifestações antiglobalização que acompanharam sistematicamente as reuniões de grandes organismos internacionais como a da Organização Mundial do Comércio (Genebra - Suíça, maio de 1998); do G855 (Colônia Alemanha, maio de 1999); da chamada "rodada do milênio", cancelada em função dos protestos (Seattle Estados Unidos, novembro de 1999); do Fundo Monetário Internacional (Washington - Estados Unidos,

\footnotetext{
${ }^{5}$ Os sete países mais ricos do mundo mais a Rússia.
} 
abril de 2000); da Organização para a Cooperação e o Desenvolvimento Econômico (Bologna - Itália, julho de 2000); do Fundo Monetário Internacional e do Banco Mundial (Praga - República Tcheca, setembro de 2000); da Cúpula da União Européia (Nice - França, dezembro de 2000); do Fórum Econômico Mundial de Davos (Porto Alegre - Brasil, janeiro de 2001); da reunião preparatória à Terceira Cúpula das Américas (Buenos Aires - Argentina, abril de 2001); da reunião sobre a ALCA (Quebec - Canadá, abril de 2001). ${ }^{6}$

A lista poderia ser completada com datas posteriores, e também preenchida com muitas outras manifestações mais pontuais. Em 15 de fevereiro de 2003 aconteceu uma das maiores e mais bem orquestradas manifestações em nível mundial: a invasão do Iraque por um exército liderado pelos Estados Unidos e pela Inglaterra levou às ruas de 528 grandes cidades milhões de pessoas que conclamavam as lideranças mundiais a buscarem solucionar os problemas mundiais por meios pacíficos. Essas manifestações se alimentam do mesmo "caldo político e cultural"7 do Fórum, um caldo que se origina das políticas excludentes e promotoras de desigualdade, legitimadas por organismos internacionais não-democráticos e pela acumulação de riquezas e de poder em alguns centros que passam a controlar o mundo com a lógica do mercado.

A reação não se esgota em manifestações que, pela sua própria natureza, se caracterizam por certa espontaneidade. Grzybowski (2001) associa a origem do Fórum Social Mundial com a criação de redes globais de cidadania, na década de 1990, que teriam começado a pensar alternativas ao processo de globalização, unindo experiências ao redor do mundo. Entre estas redes estão nomes que foram adquirindo familiaridade global, como o Social Watch, a Via Campesina e a One World. Ao revisar a compreensão dos movimentos sociais, Ilse Scherer-Warren (1996) constata como nessa mesma década também se passa, na

${ }^{6}$ Cf. Grzybowski (2001, p. 37-40).

${ }^{7}$ Esse "caldo político e cultural" é analisado em mais detalhes por Grzybowski (2001, p. 19-29). academia, à compreensão dos movimentos como redes. É um olhar que vê o "nó" como um dos pontos de uma rede que continua sendo tramada e que, a rigor, não tem início nem fim.

Segundo Castells (1999), a construção de redes é um processo que se realiza concomitantemente à busca de identidade individual ou coletiva, fonte básica do significado social. As novas tecnologias de informação e comunicação permitem que indivíduos e grupos sejam conectados e desconectados num constante jogo de decisões estratégicas. Daí, segundo ele, que "nossas sociedades estão cada vez mais estruturadas em uma oposição bipolar entre a Rede e o Ser" (p. 23), entre o risco da fragmentação e difusão, por um lado, e o apego a fundamentalismos, por outro. $\mathrm{O}$ Fórum Social Mundial, como um movimento coletivo que ao mesmo tempo reúne diferentes tipos de rede e promove a formação de redes,${ }^{8}$ parece ter o importante papel de fazer com que rede e ser não se constituam em oposição bipolar, mas formem uma bipolaridade tensionada.

O Fórum Social Mundial pode ser visto como uma manifestação da sociedade em movimento, refletindo mudanças importantes na organização da sociedade e na compreensão que se tem dessa organização. Além da tendência de funcionar em rede, haveria ainda, segundo Dieter Rucht (2001), o enfraquecimento de movimentos sociais clássicos aos quais se devem grandes conquistas políticas da modernidade como a proclamação dos direitos universais, o voto universal e igualitário, o fim da escravidão, a escola pública universal, para citar algumas. Surgiria, por outro lado, o conceito de sociedade de movimento para referir-se à grande gama de protestos em torno de questões específicas. Ao contrário dos tradicionais

\footnotetext{
${ }^{8}$ A título de ilustração: durante o último Fórum, realizado
} em Porto Alegre, participei de duas atividades voltadas para a formação de redes: a formação de uma rede de pesquisadores sobre a temática da participação e a formação de uma rede de núcleos e grupos de pesquisa em universidades que se dedicam ao estudo dos movimentos sociais. 
movimentos sociais dedicados a uma causa, na "sociedade de movimento" teríamos alianças pontuais que utilizam o protesto como sua principal arma.

Minha "leitura" do e sobre o Fórum confirma a análise de Immanuel Wallerstein (2002), que vê nele o encontro de várias gerações e tipos de movimentos anti-sistêmicos: a antiga esquerda revolucionária; os novos movimentos sociais; organismos de direitos humanos; organizações locais, regionais, nacionais e transnacionais; iniciativas do Norte e do Sul. Daí a preferência, neste texto, pela expressão mais flexível, o ponto de vista acadêmico, de sociedade em movimento. O Fórum Social Mundial não é e não pretende ser um megamovimento social, com uma super-estrutura, uma agenda única e uma liderança centralizada. Tampouco pode ser identificado com um encontrão de protestadores globais. Ele é tudo isso, mas é mais, na medida em que conseguir resistir à tentação de enquadrar todos os sonhos e projetos dentro de um pensamento único, mesmo que progressista e alternativo.

$\mathrm{Na}$ ótica da recente experiência política brasileira, a "massa" do Fórum Social Mundial é composta de um amplo recorte da população que corresponde à volta da idéia de povo. José Murilo de Carvalho (2003) analisa como o fato de Lula vencer a eleição e assumir o governo "nos braços do povo" (frase da cartatestamento de Getúlio Vargas) lembra o estilo do nacionalismo desenvolvimentista, quando a categoria de povo teve seu conteúdo elaborado pelo Instituto $\mathrm{Su}$ perior de Estudos Brasileiros (ISEB). Reproduzo um parágrafo no qual o autor sintetiza essa idéia de povo:

O povo era a entidade que extrapolava as classes sociais. Formava-se por um corte vertical em nossa estratificação social. Incluía trabalhadores, sem dúvida, mas também camponeses, parcelas da classe média, da pequena burguesia, da intelectualidade, do empresariado. $\mathrm{O}$ povo era a grande coalizão de todos os que lutavam pela emancipação nacional. Ele era a nação que adquiria consciência de si mesma e, como tal, deveria ser o agente principal de nossa história. (Carvalho, 2003, p. 6)
Nos anos da ditadura, a noção de povo foi substituída por classe social, o que se verificou tanto no movimento sindical, na educação popular, como nas Comunidades Eclesiais de Base. No anos de 1980, segundo Carvalho, é o cidadão que assume o protagonismo político no país. A cidadania é a expressão de um tipo de modernidade que representa a possibilidade de indivíduos e grupos reclamarem o seu lugar na sociedade. A volta da idéia de povo, portanto, não significa um simples retorno ao populismo paternalista e manipulador, uma vez que décadas de lutas e conquistas fizeram com que o povo, hoje, esteja em condições de participar de uma maneira mais crítica na vida política do país. É o povo "curtido" pelas conquistas e derrotas nas lutas de sua classe e pelos direitos da cidadania. É também o povo que se vê conectado com outros povos.

A repercussão do Fórum Social Mundial tem a ver com esta participação massiva que faz com que ele penetre em diferentes segmentos e estratos da sociedade. De passagem por um pequeno município do interior do Estado do Rio Grande do Sul, chamou minha atenção um artigo no jornal local sobre a participação de vereadores do município no Fórum. A reportagem fazia referência ao problema da soberania alimentar e ao tema da água como um bem comum da humanidade. É de se imaginar que, sem a presença no Fórum, dificilmente esses temas teriam chegado a esse município, melhor ainda, chegado lá nos termos de uma problemática abrangente e internacional.

O exemplo citado mostra como o envolvimento de dezenas de milhares de pessoas faz com que as temáticas do Fórum assumam uma capilaridade praticamente incontrolável. Nossa primeira reação é ver se há alguma notícia na Folha de S. Paulo, na BBC, no Le Monde Diplomatique ou no The New York Times. São Paulo, Londres, Paris e Nova York são lugares obviamente importantes pelo seu peso político, mas a verdadeira eficácia do Fórum pode ser medida pelo fato de pessoas como esses vereadores colocarem na pauta da Câmara Municipal e da sociedade local a questão da soberania alimentar e sua relação com os 
transgênicos, ou o problema da água com a poluição dos mananciais do município com agrotóxicos.

O Fórum tem o papel fundamental de trazer para um mesmo palco de discussão as experiências locais e as reflexões num nível macro. Nesse sentido, ele é diferente de congressos acadêmicos em pelo menos dois sentidos importantes. Um deles é reunir no mesmo espaço pesquisadores de diferentes áreas; há mesas e sessões específicas, com pautas determinadas pela área, mas há também amplo espaço de interação. Um segundo sentido, mais importante, no entanto, é que mesmo o acadêmico que precisa pensar interdisciplinarmente (ou, se possível, transdisciplinarmente) se vê ao lado do ativista em movimentos sociais ou de artistas que se expressam com outras linguagens.

Assim como as atividades do Fórum fogem ao "controle", assim também as repercussões não podem ser enquadradas em metas ou reduzidas a algum tipo de produto. A leitura do vereador daquele município do interior gaúcho será diferente da leitura da prefeita de São Paulo. O militante do Movimento dos Trabalhadores Rurais Sem Terra (MST) levará ao acampamento idéias diferentes daquelas que o sociólogo seleciona para os seus seminários. No que segue, haverá uma tentativa de fazer esta leitura do ponto de vista da educação popular, um tipo de ação e concepção político-pedagógica que de forma alguma é estranho ao Fórum. A educação popular faz parte do mesmo, não só pela oferta de seminários e oficinas, mas pela sua presença nos movimentos e momentos fundacionais do Fórum. A intenção deste exercício é no sentido de tomar distância para redesenhar horizontes e revisar as intervenções pedagógicas no contexto dos desafios colocados por essa parte da sociedade global em movimento, para quem um outro mundo é possível e necessário.

\section{O Fórum e a agenda da educação popular}

O Fórum Social Mundial desafia a educação popular em três frentes. Primeiro, propõe que a educação popular se veja dentro das redes globais. Pela sua experiência, a educação popular pode dar uma impor- tante contribuição à área da educação no atual esforço de inserção internacional. Em segundo lugar, o Fórum força o repensar a questão epistemológica, jogando a educação popular no caldeirão das grandes discussões que são necessariamente multidisciplinares. Por fim, as atividades do Fórum sugerem temáticas que podem ser priorizadas pela educação popular.

\section{A educação popular como caminho para a inserção internacional}

Estamos acostumados a ver a educação popular como um fenômeno caracteristicamente latino-americano. Isso, por um lado, é verdadeiro, como atesta o fato de o maior expoente da pedagogia na segunda metade do século XX, Paulo Freire, ter iniciado sua práxis pedagógica nos embates pela cidadania (por comida, por cultura, por educação, por saúde...) na América Latina, mais precisamente no Nordeste brasileiro, uma das regiões mais pobres deste continente.

Mas esse fato é apenas parte da história. Basta um olhar rápido pelas notas de rodapé de Pedagogia do oprimido (Freire, 1981) para ver que não se tratava de um movimento limitado à América Latina, muito menos tomado de xenofobia. Ao lado de Che Guevara encontramos Mao Tse Tung e Lenin; Cândido Mendes faz companhia a Frantz Fanon e Albert Memmi; junto com a fala de um camponês, há referência a Regis Debret; José Luís Fiori está próximo de Reinhold Niebuhr. Os exemplos de uma internacionalidade das fontes poderiam ser multiplicados. Essa antena para o que estava ocorrendo no fim da década de 1960, enquanto Freire escrevia Pedagogia do oprimido, pode ser ilustrada com a primeira nota do livro, na página inicial, onde ele vincula a luta das classes marginalizadas e oprimidas da América Latina com os movimentos estudantis e das mulheres na Europa e nos Estados Unidos.

Esta discussão coloca, concomitantemente, duas questões para a educação popular. Por um lado, a educação popular latino-americana terá que fazer o movimento consciente de se vincular a outros movimentos similares ao redor do mundo. Mesmo que Freire 
tivesse essa referência internacional em sua elaboração teórica, na prática poucas conexões foram estabelecidas com experiências de outros continentes, talvez com exceção da ação educativa com jovens e adultos pelo Conselho de Educação de Adultos na América Latina (CEAAL), a partir da década de 1980. Como as últimas décadas, no Brasil, foram férteis em experiências de educação popular em escolas, ali se encontra hoje um campo propício para encetar o diálogo. Bernd Fichtner (2003) vê nas "escolas cidadãs" uma possibilidade de rever profundamente o sentido da educação pública tradicional, para a qual ele não reserva muitos motivos de glorificação, mesmo no contexto europeu. O mérito dessas escolas, como parte da educação popular, estaria em assumir-se como instrumento público da comunidade, estabelecendo através dessa postura novos parâmetros para a produção de conhecimentos.

Conforme a análise realizada acima, cabe também à educação popular encontrar o seu lugar junto às redes, ou dentro delas. A educação popular, ao longo de sua história, elaborou um instrumental teóricoprático que com certeza lhe permite acompanhar a nova dinâmica social. Penso, por exemplo, na riqueza de experiências já contadas e nas metodologias de sistematização ${ }^{9}$ que foram sendo criadas, desde a dinâmica de codificação-decodificação usada por Freire em Angicos, ao uso de imagens e outros recursos das modernas tecnologias. Em outras palavras, o momento

${ }^{9}$ Assim Oscar Jara (1996) fala de sistematização: "Parece que lo más característico y proprio de la reflexión sistematizadora sería el que ella busca penetrar en el interior de la dinámica de las experiencias, algo asi como meterse 'por dentro' de esos procesos sociales vivos y complejos, circulando por entre sus elementos, palpando las relaciones entre ellos, recorriendo sus diferentes etapas, localizando sus contradicciones, tensiones, marchas y contramarchas, llegando así a entender estos procesos desde su propria lógica, extrayendo de allí enseñanzas que puedan aportar al enriquecimiento tanto de la práctica como de la teoría” (p. 12). O número da revista Aportes no qual foi publicado esse artigo de Jara é todo dedicado à prática sistematizadora. é apropriado para lançar um novo olhar sobre o caminho já andado. ${ }^{10}$

Paradoxalmente, este movimento intencional de internacionalização forçará a busca das raízes latinoamericanas. Numa autocrítica, devemos concordar que não fizemos o suficiente para, por exemplo, recuperar para a educação popular a riqueza da tradição dos povos originários desta terra, desde seus mitos às tecnologias que haviam permitido produzir culturas como as dos incas, maias e astecas. Nunca é demais repetir a veemente denúncia de José Martí (1983) do desenraizamento de nossa reflexão, perpetuando a existência de uma cultura de togas e outra de alpargatas, de dois mundos que pouco se falam. Pouco sabemos, denunciava ele, de nossa história, uma vez que preferimos a dos outros, dos gregos e romanos, à dos incas e astecas.

A educação popular nos remete às ruas violentas e malcheirosas de nossas cidades, aos campos onde a imensidão de plantações de soja e cana convive com as lonas pretas dos acampamentos dos sem-terra. Aí encontraremos o rosto e o corpo que são a referência para a educação popular. O que Rodolfo Kusch (1986) fala de Cuzco vale para o restante da América Latina:

Porque es cierto que las calles hieden, que hiede el mendigo y la india vieja, que nos habla sin que entendamos nada. [...] Y no hay otra diferencia, ni tampoco queremos verla, porque la verdad es que tenemos miedo, el miedo de no saber cómo llamar todo eso que nos acosa y que está afuera y nos hace sentir indefensos y atrapados. (p. 11)

O medo de "contaminação" com os cheiros das ruas e dos acampamentos seria um dos motivos pelos quais a educação popular tem dificuldade de encontrar um lugar no ambiente asséptico da academia? ${ }^{11}$

${ }^{10}$ Um esforço importante de recuperação da trajetória da pesquisa em educação popular no Grupo de Trabalho (GT) da ANPEd foi realizado por Marisa Costa e Reinaldo Fleuri (2001).

${ }^{11} \mathrm{O}$ livro de Costa e Fleuri, já mencionado, reflete sobre a crise de sobrevivência do GT de Educação Popular na ANPEd. 
A busca consciente de inserção internacional também implica identificar a especificidade dos movimentos sociais e das expressões culturais latinoamericanas. Se desde o início houve interesse pela pedagogia do oprimido ou pela teologia da libertação, é porque aqui estava sendo gestado algo com que outros podiam aprender. O desafio consiste em aprofundar o conhecimento das próprias experiências em diálogo com outras.

\section{Os interlocutores da educação popular}

Um traço que caracteriza a educação popular é a sua dinamicidade. Mais do que isso, faz parte de sua trajetória uma certa irreverência. Isso talvez se deva ao fato de na sua origem haver experiências pedagógicas ligadas ao movimento anarquista. Eram pequenas escolas para filhos de trabalhadores que, pelos fins do século passado, surgiram em vários estados (São Paulo, Rio de Janeiro, Rio Grande do Sul) com o objetivo de acrescentar uma certa consciência de classe aos saberes que todas as crianças deveriam aprender (Brandão, 2002, p. 144).

A recorrência da discussão sobre o lugar da educação popular entre o formal e o não-formal é um sinal de que, mesmo com esses dois espaços da ação educativa não sendo dicotimizados, a educação popular surpreende pelo seu caráter iconoclasta, por ser demasiadamente imprevisível para a pragmática lógica institucional. ${ }^{12}$ Faz parte dessa identidade a permissão para beber de fontes consideradas pouco ortodoxas, ou de fazer sua teoria com retalhos ou fragmentos que nem sempre formam unidades redondas, sem arestas.

O Fórum Social Mundial é um lugar para se viver essa multiplicidade de interlocuções. É difícil di-

12 "La educación popular surge de la denominada 'marginalidad' y la miseria, como una propuesta de socialización que rompa la atadura educación igual escuela, como un atreverse a pensar que es posible otra forma de construir la vida, diferente a que normalmente se tenía como patrón para estos sectores" (Mejía J., 1995, p. 142). zer se os temas são colocados pela economia, pela sociologia, pela ciência política, pela antropologia ou por qualquer outra área. Trata-se de um esforço conjunto de deixar-se interpelar pela realidade, embalados pelo sonho de construção de um outro mundo.

Para a educação popular fica o desafio de buscar suas parcerias de forma aberta, fugindo da tentação dos reducionismos de que sua própria história é testemunha. O esforço de refundamentação da educação popular na década de 1990 foi originado, em parte, por estreitamentos teóricos, não mais sendo a reflexão capaz de gerar intuições e forças para dar conta da complexidade da prática educativa que a realidade exigia. Assim, a educação popular, em diferentes períodos, foi uma espécie de apêndice da economia, outras vezes da sociologia ou das ciências políticas.

Nesse diálogo, cabe-lhe construir outros critérios de rigorosidade. Um parceiro importante nessa busca continua sendo Paulo Freire, que, principalmente nos últimos escritos, tratou do tema com insistência. ${ }^{13}$ Ser rigoroso, para ele, não significa a adaptação a determinado corpo de pensamento ou a aplicação de um método. A rigorosidade está relacionada, acima de tudo, com a possibilidade de responder adequadamente a determinados desafios colocados pela própria realidade, pelos rostos e corpos que são o outro, aquele que é vitimado neste mundo e por isso se constitui como fonte para se sonhar e buscar outro mundo. A teoria é colocada em seu lugar de instrumento para a compreensão da realidade, e não como um fim em si mesma.

Nesse sentido, a educação popular nasce interdisciplinar, quando não transdisciplinar. Compete-lhe aprofundar essa dinâmica de diálogo. Ela pode ser uma espécie de plataforma em que as várias áreas se encontram. Usando uma imagem de Freire, uma espécie de sombra de mangueira onde se vai, com seus saberes, conversar para construir o outro mundo com palavras-semente.

\footnotetext{
${ }^{13}$ Ver Streck (2003).
} 


\section{Algumas questões emergentes e recorrentes ${ }^{14}$}

O Fórum Social Mundial funciona também como uma espécie de termômetro para detectar as temáticas que brotam das práticas educativas de grupos que, por sua vez, julgam importante socializá-las. Uma revisão das 1.286 oficinas oferecidas durante o III Fórum permite identificar essas temáticas, algumas delas novas, outras ressurgindo com novas feições. ${ }^{15}$ As cinco categorias a seguir procuram dar conta das principais tendências verificadas:

1. Educação e gestão democrática: Este tema ocupa um espaço muito especial nos debates que atualmente se realizam na interface do político com o pedagógico. Talvez contribua para isso o fato de o Fórum se realizar em Porto Alegre, a cidade que tem a mais longa tradição de participação popular através do Orçamento Participativo (desde 1989). Há um reconhecimento, geralmente implícito, de que a conquista da democracia e da cidadania são também processos pedagógicos. Isso põe a educação popular dentro dos debates que hoje se travam sobre o papel e o tamanho do Estado, o papel da esfera pública estatal e não-estatal, a sociedade civil e os movimentos sociais e as estruturas políticas nos diferentes níveis de organização das sociedades.

2. Educação e arte: Chama atenção o número de oficinas que trabalham a dimensão estética. Menciono alguns dos títulos: "Cultura popular: arte e música”; “Terapia e a educação po-

${ }^{14}$ As questões emergentes encontram-se misturadas com as recorrentes, como sugere o subtítulo do livro recentemente editado por Elisa Gonsalves (2002), com textos do GT de Educação Popular da ANPEd.

${ }^{15}$ Agradeço a colaboração das bolsistas de iniciação científica Rita de Cássia Machado e Cheron Zanini Moretti pelo levantamento das temáticas. pular pela arte"; "Cultura popular: arte e resistência"; "Pedagogia do encantamento"; "Poesia e mobilização social"; "O alfabeto de amor e de sonhos: o desafio das relações na constituição dos grupos sociais”. Os títulos sugerem que se está muito longe das análises de conjuntura áridas e, muitas vezes, desesperançosas. Isso não significa que a situação do povo esteja mais tranqüila. Os dados indicam o contrário. O que a temática sugere é a compreensão de que dificilmente haverá um outro mundo na ausência de poesia, do belo.

\section{Educação, sustentabilidade e trabalho: Em} poucos campos as mudanças são tão profundas e tão dramaticamente sentidas como no mundo do trabalho. Numa sociedade em que a identidade de cidadão e cidadã é dependente do trabalho (o que você faz para ganhar a vida?), o tema vem penetrando via práticas autogestionárias. Considerando que os empregados de carteira assinada passam a ser minoria (no Brasil, são $24 \%$ das pessoas economicamente ativas), é natural que surjam outras formas de organização de trabalhadores ao lado dos sindicatos. É importante notar que o tema está vinculado com a preocupação ecológica, pela noção de sustentabilidade.

\section{Educação, multiculturalismo e globalização:} Desde os círculos de cultura no projeto de Paulo Freire, o tema da cultura foi uma presença constante na educação popular na América Latina. Houve, no entanto, importantes deslocamentos do enfoque: a) não se trata mais da cultura popular num sentido de classe, em contraposição a uma cultura hegemônica, como duas grandezas mais ou menos estáticas, mas a cultura se apresenta como o espaço simbólico que habitamos e que está em constante reconfiguração; b) os meios de comunicação fizeram com que houvesse muito mais consciência de outras culturas, colocando com isso a difícil 
tarefa de dar significado para a sua própria vida individual e do grupo dentro de um amplo conjunto de possibilidades de viver e conviver.

5. Educação e gênero: Este tema vem gradativamente conquistando o seu lugar na agenda da educação popular. Mesmo havendo um razoável acúmulo de discussões, há fortes razões para reforçar o trabalho, uma vez que o tipo de economia a que estamos submetidos tende a fragilizar e sobrecarregar a mulher, ameaçando inclusive algumas de suas duras conquistas. Acontece que os ajustes em nível macro repercutem em ajustes domésticos que oneram sobretudo a mulher, fazendo-a assumir ainda mais responsabilidades na luta pela sobrevivência.

\section{Como conclusão}

A agenda da educação popular é, por natureza, aberta e dinâmica, uma vez que se conforma nas lutas por um outro mundo que se travam entre os gemidos dos que ficaram fora deste, nas marchas dos que protestam, nas disputas eleitorais e nos embates semânticos. Procurei argumentar que o Fórum Social Mundial, pela sua abrangência geográfica, ideológica e temática, é hoje um lugar privilegiado de se exercitar a escuta, de negociar estratégias e de aprimorar os instrumentos teórico-práticos de intervir na sociedade.

Isso significa estar autocriticamente atento, olhando as continuidades e mudanças, mas também identificando as ausências. Por exemplo, deveríamos perguntar por categorias analíticas que buscam compreender a nova fase do capitalismo, tendo em vista que nas últimas décadas vimos a concentração indecente dos recursos e dos bens. Pierre Bourdieu e Loïc Wacquant chamam a atenção para o que eles denominam de nova "vulgata planetária", na qual termos que serviram na luta por importantes conquistas sociais tendem a ser trocados por outros que não representam ameaça ao sistema ou até o reforçam. Numa alu- são ao multiculturalismo na versão norte-americana, eles ironizam:

Enquanto os filósofos se deliciam doutamente com o reconhecimento cultural, dezenas de milhares de crianças de classes e etnias dominadas são excluídas das escolas primárias por falta de vagas (eram 25 mil só este ano, na cidade de Los Angeles), e um jovem em dez provenientes de famílias que ganham menos de 15 mil dólares anuais tem acesso aos campi universitários, contra 94\% das crianças que dispõem de mais de 100 mil dólares. (2001, p. 158)

Há na educação popular uma espécie de espinha dorsal, constituída por uma base epistemológica e por princípios metodológicos, que lhe permite participar na construção de uma agenda que contemple ao máximo a integralidade das dimensões da vida humana, bem como as várias escalas e níveis dentro dos quais cada vida é tramada. Uma agenda que esteja impregnada das vontades e de sonhos por um outro mundo.

DANILO ROMEU STRECK, doutor em educação pela Rutgers University (The State University of New Jersey), é professor e pesquisador do Programa de Pós-Graduação em Educação da Universidade do Vale do Rio dos Sinos (UNISINOS). Publicações recentes: Pedagogia no encontro de tempos: ensaios inspirados em Paulo Freire (Petrópolis: Vozes, 2001); Educação para um novo contrato social (Petrópolis: Vozes, 2003). Projeto de pesquisa em andamento: Processos participativos emancipatórios na América Latina como mediação pedagógica para a constituição do público.E-mail: danilo@poa.unisinos.br

\section{Referências bibliográficas}

BOURDIEU, Pierre, WACQUANT, Loïc, (2001). A nova bíblia de Tio Sam. In: CATANI, Antonio David (org.). Fórum Social Mundial: a construção de um mundo melhor. Porto Alegre: Editora da Universidade; Petrópolis: Vozes, p. 156-161. BRANDÃO, Carlos Rodrigues, (2002). A educação popular na escola cidadã. Petrópolis: Vozes.

CARVALHO, José Murilo de, (2003). Lembrança de outro carnaval. Folha de S. Paulo, São Paulo, Caderno Mais!, p. 4-6, 5 jan. 
CASSEN, Bernard, (2001). Uma virada política e cultural. In: CATANI, Antonio David (org.). Fórum Social Mundial: a construção de um mundo melhor. Porto Alegre: Editora da Universidade; Petrópolis: Vozes, p. 15-18.

CASTELLS, Manuel, (1999). A sociedade em redes. $4^{\text {a }}$ ed. São Paulo: Paz e Terra.

COSTA, Marisa Vorraber, FLEURI, Reinaldo Matias, (2001). Travessia: questões e perspectivas emergentes na pesquisa em educação popular. Ijuí: Editora Unijuí.

FICHTNER, Bernd, (2003). Educação popular, educação formal. Texto apresentado no II Fórum Mundial de Educação. Porto Alegre: jan.

FREIRE, Paulo, (1981). Pedagogia do oprimido. $9^{\mathrm{a}}$ ed. Rio de Janeiro: Paz e Terra.

GONSALVES, Elisa (org.), (2002). Educação popular e grupos populares: temas (re)correntes. Campinas: Alínea.

GRZYBOWSKI, Cândido, (2001). Sim, um outro mundo é possível. In: CATANI, Antonio David (org.). Fórum Social Mundial: a construção de um mundo melhor. Porto Alegre: Editora da Universidade; Petrópolis: Vozes, p. 19-30.

JARA, Oscar, (1996). Tres posibilidades de sistematizacion: comprensión, aprendizage y teorización. Aportes, Bogotá, Dimensión Educativa, $n^{\circ}$ 44, p. 7-22, marzo.
KUSCH, Rodolfo, (1986). America profunda. $3^{\text {a }}$ ed. Buenos Aires: BONUM.

MARTÍ, José, (1983). Nossa América: antologia. São Paulo: Hucitec.

MEIRELES, Cecília, (2001). Crônicas de educação 1. Rio de Janeiro: Nova Fronteira e Fundação Biblioteca Nacional.

MEJÍA J., Marco Raúl, (1995). Educación y escuela en el fin de siglo. $5^{\mathrm{a}}$ ed. Bogotá: CINEP.

RUCHT, Dieter, (2001). Sociedade como projeto; projetos na sociedade: sobre o papel dos movimentos sociais. Civitas, Porto Alegre: EDIPUCRS, ano 1, nº 1, p. 13-28, jun.

SARAMAGO, José, (2002). O homem duplicado. São Paulo: Companhia das Letras.

SCHERER-WARREN, Ilse, (1996). Redes de movimentos sociais. $2^{\mathrm{a}}$ ed. São Paulo: Loyola.

STRECK, Danilo R., (2003). Educação para um novo contrato social. Petrópolis: Vozes.

WALLERSTEIN, Immanuel, (2002). New revolts against the system. New Left Review, $\mathrm{n}^{\mathrm{o}}$ 18, nov./dec. Disponível em: <http://www.newleftreview.net>. Acesso em: 10 jan. 2003.

Recebido em outubro de 2003 Aprovado em dezembro de 2003 
Palavras-chave: trabalhador rural; participação; esfera pública

The contribution of the ordinary man to the construction of the public sphere: rural workers in Baturité State of Ceará

Analyses the participative experience of the ordinary man - the rural landless worker, lease-holder or tenant farmerin public spaces like municipal councils, associations of small producers and the Rural Workers' Trade Union, in Baturité, a municipality of 30,000 inhabitants in the State of Ceará. The research took as its starting point a basic question: how does the ordinary man experience politics today?

Understanding politics as transgression, dispute or the changing of positions, achieved by means of discussion and demands, and by examining the possibility of constructing a public sphere, the research followed systematically the participative experiences of two rural communities, which are characterised as State offers and as civil society conquests. The participative dynamic is established by involving conflicting movements which at times are characterised as democratic and transparent relations between State and civil society and, at others, as traditional relations based on authoritarianism and cordiality, salient features of Brazilian political culture. Although the material conquests of the associative experiences are limited, gradual approximations to a style of democratic being are experienced and these, in turn, signal the production of a legacy: the quest for citizenship and the awareness of rights.

Key-words: rural worker; participation; public sphere

Neusa Maria Dal Ri e Candido Giraldez Vieitez

\section{A educação do movimento dos sem-} terra
O Instituto de Educação Josué de Castro, que tem como mantenedor o Instituto Técnico de Capacitação e Pesquisa da Reforma Agrária e é vinculado ao movimento dos sem-terra, constituise em uma escola de educação média e profissional. O objetivo desse texto é o de expor os elementos educativos principais presentes na escola, bem como elucidar se a sua concepção educacional, que parece ser a mesma vigente nas escolas controladas pelo MST, contém elementos educacionais de interesse para as classes trabalhadoras em geral, do ponto de vista democrático e popular. A investigação revelou que o Instituto, estruturado e organizado de forma diferente daquela usualmente encontrada nas escolas oficiais, coloca em epígrafe categorias educacionais como a união do ensino com o trabalho e a gestão democrática compartilhada entre alunos, professores e funcionários.

Palavras-chave: educação; trabalho; autogestão

\section{Education in the Landless Workers'} Movement

The Josué de Castro Institute of Education, sponsored by the Technical Institute for Training and Research into the Agrarian Reform, which is associated with the landless workers' movement, provides both secondary education and technical training. The aim of this paper is to explain the principal features of this school, and to clarify whether its underlying educational premises, which seem to be similar to those extant in the schools under MST control, contain educational characteristics which are of interest to the working classes in general, from a democratic and popular point of view. The investigation showed that the Institute, whose structure and organisation differ from those commonly found in state schools, takes as its motto such educational categories as the union between education and work and democratic management processes in which students, teachers and school staff participate.

Key-words: education; work; selfmanagement

Danilo Romeu Streck

\section{O Fórum Social Mundial e a agenda} da educação popular

Realiza uma leitura do III Fórum Social Mundial, a partir da perspectiva da educação popular. Trata inicialmente dos objetivos e da dinâmica do Fórum para depois identificar temas que recomponham a agenda da educação popular. O primeiro deles refere-se à necessidade e às possibilidades de a educação popular ser pensada internacionalmente. $\mathrm{O}$ segundo trata da pluralidade de aportes e dos consequientes desafios epistemológicos e metodológicos. Por fim, são identificados alguns temas emergentes ou recorrentes, com base nas 1.286 oficinas oferecidas no Fórum.

Palavras-chave: Fórum Social Mundial; educação popular

The World Social Forum and the agenda for popular education.

This article presents a reading of the III World Social Forum, based on a popular education perspective. It deals initially with the goals and the dynamic of the Forum and then identifies themes which restructure the agenda for popular education. The first of these refers to the need and the possibility of popular education being discussed internationally. The second deals with the plurality of contributions and the consequent epistemological and methodological challenges. Finally some of the emerging or recurrent themes are identified based on the 1,286 workshops offered during the Forum. Key-words: World Social Forum; popular education 